\title{
A CONSTRUÇÃO DO PÂNICO MORAL A PARTIR DAS QUESTÕES DE GÊNERO E SEXUALIDADES NOS DISCURSOS ULTRACONSERVADORES NO BRASIL
}

\author{
Cleide Ester de Oliveira*, Nadir de Fátima B. Bittencourt** \\ Veralúcia G. de Souza***, Paulo Sesar Pimentel \\ Kátia Terezinha P. Ormond ${ }^{* * * *}$, Isabel Cristina Silva ${ }^{* * * * * *}$
}

\section{Resumo}

A discursividade de líderes políticos e religiosos brasileiros a respeito de gênero e sexualidades contribuiu para levar o pânico moral à sociedade, levando-a a reproduzir esses discursos. O objetivo deste artigo é analisar, a partir do aporte teórico da arqueogenealogia de Foucault, como esses discursos são reproduzidos. As categorias abordadas são: discurso, poder/saber/verdade e normatização. Com uma abordagem qualitativa, foram analisados vídeos do YouTube com pronunciamentos de líderes políticos religiosos brasileiros. Ancorados na Análise do Discurso, a partir das categorias: Quem fala? De onde fala? Que efeitos de sentido geram? podemos perceber que os sujeitos são atravessados por discursos de cunho moral, religioso e pseudocientífico que sustentam a heteronormatividade e os grupos que não se enquadram nesse padrão são excluídos.

Palavras-chave: Gênero, sexualidades, educação, pânico moral, exclusão.

\begin{abstract}
Gender and sexualities used in construction of moral panic in ultraconservative political speeches in Brazil

The discourse of Brazilian political and religious leaders regarding gender and sexualities contributed to bring moral panic to society, leading it to reproduce these discourses. The aim of this paper is to analyze, based on the theoretical contribution of Foucault's archeo-genealogy, how theses discourses are reproduced. The addressed categories are discourse/power/truth and normatization. With a qualitative approach, YouTube videos with statements of Brazilian religious political leaders were analyzed. Anchored in Discourse Analysis, from the categories: Who speaks? Where are you talking from? What effects of
\end{abstract}

* Grupo de Pesquisa em Humanidades e Sociedade Contemporânea. Instituto Federal de Educação, Ciência e Tecnologia de Mato Grosso (IFMT), Brasil.

Endereço postal: Av. Sen. Filinto Müller, 953 - Quilombo, Cuiabá - MT, 78043-400, Brasil.

Endereço eletrónico: cleidester@hotmail.com

ORCID: https//orcid.org/0000-0002-5094-235X

** Endereço eletrónico: nadir.bittencourt@cba.ifmt.edu.br

ORCID: https//orcid.org/0000-0002-0021-5437

*** Endereço eletrónico: veralucia.souza@blv.ifmt.edu.br

ORCID: https//orcid.org/0000-0003-1038-7387

**** Endereço eletrónico: paulo.pimentel@blv.ifmt.edu.br

ORCID: https//orcid.org/0000-0002-2233-3100

***** Endereço eletrónico: katia.ormond@blv.ifmt.edu.br ORCID: https//orcid.org./0000-0002-0118-023X

****** Endereço eletrónico: isabel.silva@plc.ifmt.edu.br ORCID: https://orcid.org/0000-0003-0280-1322 
meaning do they generate? we can notice that the subjects are crossed by moral, religious and pseudoscientific discourses that support heteronormativity and the groups that do not fit this pattern are excluded.

Keywords: gender; sexuality, education, moral panic, exclusion.

\begin{abstract}
Resumen
Género y sexualidades utilizados en la construcción del pánico moral en los discursos ultraconservadores en Brasil

El discurso de los líderes políticos y religiosos brasileños sobre género y sexualidades contribuyó a llevar el pánico moral a la sociedad, llevándola a reproducir estos discursos. El objetivo de este artículo es analizar, con base en la contribución teórica de la arqueo-genealogía de Foucault, cómo se reproducen estos discursos. Las categorías abordadas son: discurso, poder/saber/verdad y normatización. Con un enfoque cualitativo, se analizaron videos de YouTube con declaraciones de líderes políticos y religiosos brasileños. Anclado en el análisis del discurso, a partir de las categorías: ¿Quién habla? ¿De dónde habla? ¿Qué efectos de sentido generan? podemos percibir que los sujetos están atravesados por discursos de naturaleza moral, religiosa y pseudocientífica que sostienen la heteronormatividad y los grupos que no se ajustan a este patrón están excluidos.
\end{abstract}

Palabras-clave: Género, sexualidades, educación, pánico moral, exclusión.

\title{
Introdução
}

As discussões sobre gênero e sexualidades têm-se tornado assunto polêmico na sociedade brasileira. Este tema fez parte de embates no campo da política na última década (Oliveira 2014) e, em 2018, deu a vitória a um candidato ultraconservador que se utilizou destes tópicos para criar pânico moral na sociedade, ao distorcer projetos e propostas educacionais que visavam combater a LGBTfobia e trazer as discussões sobre gênero para o interior das escolas.

Determinados setores de nossa sociedade - hoje representados politicamente no executivo federal - exigem que nossa identidade seja única, fixa, estável e em acordo com a biologia, ou seja, que mostremos um sexo verdadeiro, ajustado à norma heterossexual. Como característica desta exigência, há o estabelecimento de um padrão de normalidade, resumido ao conjunto binário: mulher=feminina, homem=masculino. Essa construção tem origem em um possível determinismo biológico, cujos corpos são compreendidos no dismorfismo macho-fêmea. Isso significa que homens e mulheres são representados em suas anatomias de forma estável e delimitada em papéis sociais masculinos e femininos. Ser homem corresponde a rejeitar todo e qualquer traço que identifique o universo feminino (Reis e Pinho 2016).

Para este segmento social, não há outra possibilidade fora desse modelo dualista e hierarquizado. Ainda hoje, identidades e sexualidades que fogem a esse padrão são consideradas algum tipo de perturbação ou patologia mental, emocional ou física. Estudos, no entanto, apontam para o fato de que considerar o sexo, o 
desejo, o gênero e as sexualidades como fixos e indiscutíveis provoca atitudes de violência, exclusão e torna difícil - ou impossível - a vida de muitos indivíduos (Junqueira 2009; Borillo 2010; Oliveira 2014).

O Grupo de Pesquisa em Humanidades e Sociedade Contemporânea (GPHSC), ${ }^{1}$ do qual fazemos parte, conta com pesquisadores das várias áreas das ciências humanas e sociais. Os pesquisadores buscam interpretar a sociedade contemporânea, a partir de diferentes concepções teóricas e autores, descrevendo e analisando através de diferentes ângulos os mesmos fenômenos: violência, discriminação, preconceito, xenofobia, direitos humanos e bullying.

A partir do ano 2000 - em função da organização e mobilização de grupos representantes do movimento LGBT (lésbicas, gays, bissexuais e transgêneros) reivindicando seus direitos de cidadania -, foi identificada, por parte dos gestores públicos, a necessidade de elaborar um programa de combate à LGBTfobia mais consistente. Para dar início a esse programa, a UNESCO (Organização das Nações Unidas para a Educação, a Ciência e a Cultura), em parceria com o MEC (Ministério da Educação e Cultura), realizou uma pesquisa sobre o «Perfil dos Professores Brasileiros», entre abril e maio de 2002, com cinco mil professores da rede pública e privada. Os dados indicaram que 59,7\% deles não admitem que uma pessoa tenha relações homossexuais e 21,2\% deles não gostariam de ter vizinhos homossexuais (Abramovay, Castro e Silva 2004).

Entre os anos de 2016 e 2018, um grupo de pesquisa de Mato Grosso/Brasil, composto por pesquisadores de diversas áreas e formações, realizou um estudo qualitativo, através de questionário online, com a temática: Bullying e Violação dos Direitos Humanos. Nessa pesquisa, foram entrevistados 615 estudantes do ensino médio. Desse total, aproximadamente 5\% afirmaram que já sofreram humilhação por sua orientação sexual. Nas questões propostas no questionário, os pesquisadores solicitavam aos/às discentes sugestões para acabar com o bullying. Dentre as respostas, muitos enxergam a violência como alternativa para a solução do problema, como é possível perceber nas seguintes falas dos estudantes: «'Caso continuar, revidar violentamente', ou ainda, 'Violência se combate com violência'» (Silva, Silva, e Mota 2018).

Para romper com essa lógica de naturalização da exclusão de determinados grupos sociais, no ano de 2004, o MEC, em parceria com a UNESCO, lançou a Coleção Educação para Todos, inaugurando um espaço para divulgação de textos, documentos, relatórios de pesquisas e eventos, estudos de pesquisadores, acadêmicos e educadores nacionais e internacionais que têm por finalidade aprofundar o debate em torno da busca de uma educação abrangente e democrática (Oliveira 2014).

Esse material, chamado por seus detratores de kit gay, suscitou polêmicas de ordem social, religiosa e política bastante complexas e de repercussão nacional,

1 CAAE: 60165016.0.0000.5165/ Número do Parecer do Comitê de Ética: 1.773.781. 
gerando reações de pânico moral no país inteiro. O confronto se estabeleceu de forma acirrada nos meios de comunicação: de um lado, alguns religiosos e políticos com características conservadoras e também cidadãos brasileiros que apoiam a ideologia LGBTfóbica; do outro, o Ministro da Educação e uma parte da sociedade que acompanha as transformações e reivindicações dos direitos das minorias como um exercício democrático cidadão. Nessa queda de braço, por forte pressão da bancada religiosa, que é formada por parlamentares de diferentes denominações religiosas no Congresso Nacional, o projeto foi engavetado em 2011 com o veto da Presidente Dilma, que cedeu às pressões (Oliveira 2014).

Sobre orientação sexual e gênero, o Conselho Nacional de Educação (CNE) acatou a sugestão do MEC e excluiu da Base Nacional Curricular Comum (BNCC) os termos relacionados à questão de gênero e orientação sexual. No parecer, a justificativa é que a temática "gênero» foi objeto de muitas controvérsias durante os debates públicos da BNCC.

Como reação, houve a utilização do termo «ideologia de gênero», criado recentemente no interior de alguns discursos religiosos e políticos, que não reflete o entendimento de "gênero» presente no contexto educacional, nas práticas docentes ou na formação de professores (Borges e Borges 2018). A «ideologia de gênero», segundo seus defensores, portanto, levaria à destruição da família tradicional, à legalização da pedofilia, do aborto, incentivaria o homossexualismo [sic], anularia a diferença entre homem e mulher, etc. Enfim, levaria ao fim a ordem natural e as relações entre os sexos.

Os bispos da regional Sul da Conferência Nacional dos Bispos do Brasil (CNBB) emitiram nota em que destacam os riscos da inclusão da ideologia de gênero nos planos estadual e municipal de educação. Segundo a nota:

a ideologia de gênero sustenta que a pessoa humana é sexualmente indefinida e indefinível. Elimina-se a ideia de que os seres humanos se dividem em homem e mulher. Para além das evidências anatômicas, entendem que esta não é uma determinação fixa da natureza, mas resultado de uma cultura ou de uma época. Para a ideologia de gênero, o «natural» não é tido como valor humano e é preciso superar até mesmo a distinção da natureza masculina e feminina das pessoas. Com o intuito de superar discriminações, desconsideram-se as diferenças. Acusa-se que as explicações naturais são formulações ideológicas para manter determinada posição social. Como consequência da questão de gênero, promove-se a desvalorização da família em favor da liberdade individual, desconsidera-se a maternidade natural e o matrimônio, e desprezam-se os valores religiosos. (apud Borges e Borges 2018, 15)

A imagem que se faz é que todo menino/menina poderia se tornar transgênero (a), segundo essa ideologia, seria ensinado nas escolas que ser menino ou menina são construções culturais e sociais. No entanto, o discurso sobre igualdade de gênero presente nas diretrizes curriculares de muitas escolas brasileiras 
não deve ser tratado como ideologia de gênero, uma vez que igualdade de gênero sempre ressaltou a importância da igualdade das condições de gênero, ou seja, que homens e mulheres tenham as mesmas condições em todos os espaços sociais (Ministério da Educação, 2012).

Aqueles que apregoam a existência de uma ideologia de gênero utilizam argumentos sem fundamentos científicos, replicando-os nas mídias sociais para persuadir a população que os aceitam como verdades inquestionáveis, o que causa o pânico moral.

O termo pânico moral é associado a Stanley Cohen, que, em 1972, o utilizou em referência aos confrontos e episódios de vandalismo protagonizados por grupos de jovens rivais na Inglaterra, na década de 1960, o que levou o autor a formular a primeira teoria do pânico moral. Seu estudo consistiu em analisar a reação das pessoas diante de situações em que se sentiam ameaçadas por alguns grupos ou tipos sociais. Diante dessas situações de perigo, «desencadeia-se um processo de sensibilização social que resulta em forte reação coletiva contra o(s) agente(s) que causa(m) o medo coletivo» (Barros e Lemos 2018, 293). A partir daí, há uma disputa em nome do restabelecimento da ordem e da moral, em que se tenta atribuir a culpa da desordem a um grupo específico, estigmatizando-o negativamente.

Segundo Miskolci, «o conceito de pânico moral permite lidar com processos sociais marcados pelo temor e pela pressão por mudança social» $(2007,112)$, que pode ser estruturado por políticas simbólicas, sempre ancorado em valores e visões de mundo do grupo que se sente ameaçado. Ou seja, reflete anseios de poder entre grupos sociais. O pânico é moral porque aciona uma suposta ameaça à ordem social. Desse modo, questiona-se, no contexto contemporâneo brasileiro, se há nos discursos proferidos por algumas personalidades políticas e religiosas a subversão dos conceitos de gênero e sexualidades - tratados como «ideologia de gênero» [sic] - na instauração de um regime de saber, poder e verdade atravessado pelo pânico moral.

\section{Fundamentação teórica: $\mathrm{O}$ edifício da teoria - Discurso}

No edifício teórico da análise do discurso, é ponto fundamental trazer os conceitos formulados por Michel Foucault ([1969] 2000) no plano discursivo. Foucault define discurso como «práticas que obedecem regras». Ao aprofundar essa definição, estabelece-se que discurso é um conjunto de enunciados que foram praticados ao longo do tempo e estão sob uma determinada formação discursiva. Essa formação é «uma regularidade (uma ordem, correlações, posições e funcionamentos, transformações)» (Foucault [1969] 2000, 43) que existe. Se não for possível encontrar um sistema, uma regularidade na dispersão desses enunciados, para Foucault, não há um discurso. O autor também argumenta que, no discurso, há uma luta pelo poder na sociedade. Nele, também se traduzem os embates que 
engendram sistemas de dominação. Há, ainda, nos discursos, a luta pelo poder que se quer conquistar.

Nesse sentido, o que está na base desse conceito é a ideia de que em toda sociedade há um certo número de procedimentos que controlam, selecionam, organizam e redistribuem simultaneamente a produção do discurso (Foucault [1969] 2000). A função desses procedimentos é a de «conjurar seus poderes e perigo, dominar seu acontecimento aleatório, esquivar sua pesada e temível materialidade» (Foucault [1970] 2013, 9). Em nossa sociedade, os procedimentos de exclusão, externos ao discurso, mas em atuação sobre eles, são a palavra proibida, a segregação da loucura e a vontade de verdade. O primeiro desses procedimentos, que se constitui como a interdição, segundo Foucault ([1969] 2000), é o mais conhecido. O filósofo argumenta que nem tudo pode ser dito em qualquer circunstância e não é qualquer um que pode falar de qualquer coisa. Nesse processo de interditar o que se diz, Foucault aponta três manifestações: o tabu do objeto; o ritual da circunstância; e o direito privilegiado ou exclusivo do sujeito. A sexualidade e a política são o alvo dessas interdições.

Nessa perspectiva, para justificar certas práticas, circula um discurso e certos procedimentos que permitem controlar e impor certas regras, de forma que se estabelece quem tem acesso a esses discursos (Foucault [1969] 2000). Nesse caso, há uma ordem do discurso e, para entrar nela, há certas exigências, atendidas no entrecruzamento das categorias internas e externas com o terceiro grupo de procedimentos, formado pelos rituais da palavra, pelas sociedades do discurso, pela doutrina e pelas apropriações sociais. Destaca-se, nesse grupo de procedimentos, o ritual e as sociedades do discurso. O primeiro determina propriedades singulares e papéis preestabelecidos para os sujeitos que falam; de acordo com Foucault, os vários tipos de discursos, como os religiosos, judiciários, terapêuticos e, de certa forma, também o discurso político exigem ritual específico. Para que o controle funcione, entra em cena o segundo: é preciso uma «Sociedade do Discurso» que carregue a função de produzir, conservar e distribuir os discursos de acordo com regras estritas (Foucault [1969] 2000).

É importante destacar que, para Foucault ([1970] 2013), o poder não existe em si. Ele está sempre em relação. Todos os atores envolvidos nas relações de poder nelas agem e por elas são afetados. Desse modo, nas sociedades, os processos de subjetivação - ou seja, de formação dos sujeitos - são resultado das relações de poder. Deleuze ([1986] 2005), ao analisar as teorias foucaultianas, na proposta de tratar de elementos e relações, mutáveis e móveis, diferencia violência, força - ou poder - e saber. Na violência, há ação sobre um corpo, sobre determinadas coisas, que «ela força, dobra, quebra, destrói» (Foucault [1982] 2013, 287; Deleuze 2005, 38). Já nas relações de poder, há um modo de ação que não age diretamente e imediatamente sobre os outros, mas uma ação que age sobre ações. Os deslocamentos nesta vontade de verdade continuaram no corpo da história. Foucault cita as mudanças promovidas pela ciência, que podem ser vistas como descobertas, mas 
também como o aparecimento de novas formas de verdade. Como exemplo, há a Inglaterra dos séculos XVI e XVII. A vontade de saber ordenava ao sujeito «certa posição, certo olhar e certa função (ver, em vez de ler, verificar, em vez de comentar)» (Foucault [1976] 2011, 16). Este empirismo possui um suporte institucional, reforçado e movido por «um conjunto de práticas que vão desde a pedagogia até a sistematização do conhecimento, na forma como se organizam os livros, as bibliotecas, os laboratórios, etc.» (Foucault [1976] 2011, 17).

Diante da perspectiva sustentada pela «hipótese repressiva», que considera que o poder é um instrumento repressivo e sua função seria o de bloquear ou distorcer a verdade, Foucault ([1976] 2011) sugere uma proposta resolutiva entre poder, sexo e verdade e introduz o tema da biopolítica e do biopoder. Esse último se constituiria como poder sobre a vida (políticas de sexualidade), mas também como poder sobre a morte (racismo moderno). Em última instância, trata-se da estatização da vida, considerada em temos biológicos. A biopolítica nomeia uma forma de poder que, no fim do século XVIII e no início do século XIX, se transforma com o objetivo de governar não só o indivíduo, mas o coletivo, a população, a sociedade. Esse controle se manifestaria através não apenas da disciplinarização dos corpos, mas das mentes.

\section{Metodologia}

Nesta pesquisa, adotou-se a abordagem qualitativa, uma vez que, segundo Minayo, essa abordagem «se aplica ao estudo da história, das relações, das representações, das crenças, das percepções e das opiniões, produtos das interpretações que os humanos fazem a respeito de como vivem, constroem artefatos e a si mesmos, sentem e pensam» $(2010,57)$. De acordo com essa autora, o método qualitativo é o que se adapta às investigações de grupos e segmentos delimitados e focalizados, de histórias sociais sob a ótica dos atores, de relações, de discursos e de documentos. Sendo assim, esta pesquisa classifica-se como descritivo/ interpretativa.

Para este estudo, utilizou-se como corpus os vídeos transcritos do site YouTube contendo pronunciamentos de líderes (deputados federais e senadores) contrários às políticas de combate à LGBTfobia em exercício do mandato Legislativo no período de 2010 a 2012 e os pronunciamentos de posse do atual presidente e dois de seus ministros - em janeiro de 2019 -, estes como reverberações daqueles. A partir do site de buscas www.google.com.br, foram colocadas as palavras-chave: homofobia, kit gay, preconceito, discriminação, pregação, ideologia de gênero, educação, seguidas das palavras vídeos YouTube. Foram escolhidos os vídeos com maior número de acessos, considerando as personalidades políticas e/ou religiosas de maior destaque em cada período. 
O primeiro grupo de participantes foi selecionado devido à repercussão de seus pronunciamentos na sociedade e, também, por estar entre os primeiros a utilizar, publicamente, no Brasil, os termos «Kit gay» e «Ideologia de gênero», relacionando-os a um discurso religioso moralizante para a incitação de Pânico Moral a partir da escola; o segundo, em consonância com o primeiro grupo, pela relevância dos cargos que ocuparam em 2019.

O presente estudo tem como pressupostos teóricos e metodológicos a Análise do Discurso (AD). No livro Arqueologia do Saber, Michel Foucault ([1969] 2000) concebe que é preciso acolher o discurso em sua dimensão de acontecimento, isto é, cada texto, cada palavra, por mais que se aproxime de outros, nunca é idêntico ao que o precede. Segundo Gregolin (2007), Michel Foucault delineia as questões no interior das quais uma teoria de análise do discurso é pensada e tem como pontos fundamentais os seguintes conceitos:

a) o discurso é uma prática que provém da formação dos saberes e que se articula com outras práticas não discursivas; b) os dizeres e fazeres se inserem em formações discursivas, cujos elementos são regidos por determinadas regras de formação; c) o discurso é um jogo estratégico e polêmico, por meio do qual constituem-se os saberes de um momento histórico; d) o discurso é o espaço em que saber e poder se articulam (quem fala, fala de algum lugar, baseado em um direito reconhecido institucionalmente); e) a produção do discurso é controlada, selecionada, organizada e redistribuída por procedimentos que visam a determinar aquilo que pode ser dito em um certo momento histórico. (Gregolin 2007, 14-15)

Essa perspectiva, conforme Gregolin, tem como objetivo «analisar as condições que permitem o aparecimento de certos enunciados e a proibição de outros» $(2007,15)$. Nesse sentido, para a análise do discurso, neste trabalho, toma-se Gregolin, que usa Foucault como a referência para proceder à análise dos dados, além do próprio Foucault, que, embora não proponha um método, tece em Arqueologia do Saber e A ordem do discurso um percurso teórico e metodológico acerca do discurso.

Nesse sentido, Foucault ([1969] 2000) propõe um trabalho de descrição sobre o arquivo entendido por ele, não a massa de textos recuperados de uma época, mas o conjunto das regras que em um tempo e em um lugar definem sobre o que se pode falar, quais discursos circulam e quais se excluem, quais são válidos, quem os faz circular e através de que canais. A análise arqueológica focaliza na dimensão de exterioridade dos discursos e busca suas condições de existência nas práticas discursivas, que são também práticas sociais. As práticas discursivas produzem saberes de diferentes tipos que as caracterizam e delimitam suas especificidades (Foucault [1969] 2000).

De acordo com esse autor, para compreender por que apareceram em certo tempo e lugar uma ciência, uma teoria, um conceito, valores, verdades, etc. é pre- 
ciso atentar para as relações sociais que os tornaram discursos enunciáveis e visíveis, ou seja, situá-los em determinadas relações de poder. Nesse sentido, o saber se liga ao poder. Analisar discursos significa, para Gregolin, «tentar compreender a maneira como as verdades são produzidas e enunciadas» $(2007,15)$. Para analisar o pronunciamento dos líderes políticos e religiosos, utilizamos, neste trabalho, a Análise do Discurso (AD) (Gregolin 2006), cuja proposta de análise tem como base as seguintes categorias: Quem fala? De onde fala? Que efeitos de sentido geram? Que discursos aparecem (enunciados, contradições, repetições, regularidades e dispersões)? A partir de que grande acontecimento os discursos emergem?

De acordo com Gregolin (2006), o sujeito do enunciado, sendo historicamente determinado, não pode ser reduzido aos elementos gramaticais. Sendo assim, o sujeito não é o mesmo de um enunciado a outro e a função enunciativa pode ser desempenhada por diferentes sujeitos. Foucault explica que

não é preciso, na verdade, reduzir o sujeito do enunciado aos elementos gramaticais de primeira pessoa que estão presentes no interior da frase: inicialmente, porque o sujeito do enunciado não está dentro do sintagma linguístico; em seguida, porque um enunciado que não comporta a primeira pessoa tem, ainda assim, um sujeito; enfim e sobretudo, todos os enunciados que têm uma forma gramatical fixa (quer seja em primeira pessoa ou em segunda pessoa) não têm um único e mesmo tipo de relação com o sujeito do enunciado. (Foucault [1969] 2000, 104)

Isso significa que o autor da formulação pode não ser o mesmo sujeito do enunciado, já que esse lugar é determinado e vazio. Sendo assim, indivíduos diferentes podem ocupá-lo. Mas é também variável e pode continuar idêntico a si mesmo por meio de várias frases, assim como para se modificar cada uma (Foucault [1969] 2000). Sendo assim, o sujeito é uma posição. O mesmo indivíduo pode assumir várias posições de sujeito em um conjunto de enunciados, ou seja, na categoria de análise Quem fala? o sujeito pode não ser o mesmo autor da formulação.

Cabe destacar, também, o lugar social de onde o sujeito fala. É esse lugar que define o que pode e deve ser dito, pois é governado por regras anônimas. O sujeito é definido pelo lugar de onde ele fala. Foucault explica que «não importa quem fala, mas o que ele diz não é dito de qualquer lugar. É considerado, necessariamente, no jogo de uma exterioridade» ([1969] 2000, 139). Sendo assim, também se analisa a categoria De onde ele fala?

Ainda que palavras e textos se aproximem de outros, eles não são idênticos aos que os precedem. $\mathrm{O}$ enunciado produz um efeito de sentido pela sua correlação com um conjunto de formulações que coexistem com ele em um espaço delimitado historicamente. Isso significa dizer que o efeito de sentido de um enunciado deve ser visto dentro de uma historicidade. 
Esta análise é um recorte de uma pesquisa intitulada Discursos, Homofobia e Políticas de Direitos Humanos (Oliveira 2014), realizada entre 2010 e 2014, com a inclusão de alguns dados atuais.

\section{Análise e discussão dos dados}

\section{Deputado Federal Jair Bolsonaro}

Pronunciamento sobre o Projeto Escola sem Homofobia (Kit gay) do Deputado Jair Bolsonaro em 2010. Ele foi reeleito Deputado Federal, já pertenceu a vários partidos e esse era o seu quinto mandato como deputado. $\mathrm{O}$ seu pronunciamento foi proferido no espaço destinado à sessão plenária da Câmara Federal. Esses discursos emergiram a partir de um acontecimento, a iniciativa do MEC em elaborar um kit de material educativo, abordando aspectos da homo-lesbo-transfobia no espaço escolar, direcionado para gestores, educadores e estudantes do Ensino Médio.

No pronunciamento do Deputado Jair Bolsonaro, quem fala é um parlamentar que ocupa o lugar de representante da casa e expressa, com sentimentos de revolta e indignação, suas opiniões a respeito do tema com o objetivo de convencer os colegas da sua luta para impedir que o Projeto Escola sem Homofobia siga em frente. Ao identificar-se, o «eu» é predominante no sujeito da enunciação. $O$ «eu» que fala mostra a sua indignação em relação à proposta do kit gay que pode ser vista nos seguintes trechos:

Eu quero tratar de um assunto aqui que no meu entender, pra mim, em 20 anos de congresso é o maior escândalo que eu tomei conhecimento até hoje. [...] eu não sei pra não ser advertido nesse discurso, eu vou poupar o adjetivo pra essa comissão. ${ }^{2}$

No entanto, quando aparece como «nós», quem fala pode ser identificado, também, no trecho seguinte, como fazendo parte da sociedade, ou seja, a maioria que estaria sendo afrontada pela minoria:

Esses gays, lésbicas querem que nós, a maioria, entubemos como exemplo de comportamento a sua promiscuidade. [...] que nós não podemos nos submeter ao escárnio da sociedade. Pelo amor de Deus, meus colegas que estão nos gabinetes! Pelo amor de Deus, daqui a pouco vem um cidadão dizer que eu estou mentindo. [...] Atenção pais! Os seus filhos vão receber no ano que vem um kit, esse kit tem o título: combate à homofobia, mas na verdade esse kit é um estímulo ao homossexualismo, é um

Conforme vídeo com o pronunciamento do deputado federal Jair Bolsonaro disponível em $<$ https://www.youtube.com/watch?v=ONfPCxKdGT4\&feature=player_embedded $>$. 
incentivo à promiscuidade, [...]. Atenção pais! A tua filha de sete, oito, nove, dez anos vai assistir esse filmete que já está sendo licitado. ${ }^{3}$

No conjunto de enunciados acima, identifica-se que o espaço do dizer é ocupado por diferentes sujeitos, uma vez que a concepção com a qual se opera neste artigo não é a de sujeito unificante, pois o discurso é atravessado pela dispersão que decorre das várias posições discursivas que o sujeito do discurso assume (Gregolin 2007). O Deputado fala do lugar de parlamentar que tem 20 anos de carreira e por isso classifica o projeto Escola sem Homofobia como o maior escândalo já visto durante os seus 20 anos com tal função. Esse lugar de parlamentar ocupado por ele é atravessado por um sujeito que ocupa o lugar de maioria da sociedade e que concebe o grupo LGBT como uma minoria sem direito a voz. Ao enunciar que a plateia é composta $100 \%$ de gays, lésbicas, bissexuais, travestis, transexuais e transgêneros e que essa turma toda reunida tomou decisões que a casa desconhece (essas decisões referem-se ao kit que faz parte do projeto Escola sem Homofobia) revela um sujeito indignado com fato de um grupo com essa qualificação tomar decisões que interferirão na educação de crianças em relação à sexualidade, incentivando-as a tornarem-se homossexuais e promíscuos. Esse discurso heterossexista vem ao encontro do que afirma Borillo (2010) sobre o fato de que a heterossexualidade é vista como possibilidade única e verdadeira e a relação entre pessoas do mesmo sexo é caracterizada como uma doença degenerativa da sociedade. Além disso, o discurso que o Deputado dirige aos pais das crianças que frequentam a escola pública tem o objetivo de causar o pânico moral, fazendo com que a sociedade em geral alimente ainda mais o ódio e a rejeição aos indivíduos homossexuais. O seu modo de olhar a figura humana do homossexual é estigmatizante, já que defende uma concepção que considera o tema da diversidade sexual como um assunto proibido. O lugar discursivo que o Deputado ocupa é usado para legitimar o ódio aos homossexuais. Nesse sentido, encontramos uma correlação com que o aponta Foucault ([1970] 2013) sobre o fato de que há um certo número de procedimentos que controlam, selecionam, organizam e redistribuem simultaneamente a produção do discurso em toda sociedade. Segundo o autor, em nossa sociedade, existem procedimentos de exclusão, sendo que a interdição é a mais conhecida. Há que se considerar que a ação do parlamentar visa proibir qualquer discussão referente ao combate ao preconceito e à discriminação. Segundo o deputado, em apelo à sociedade e, em especial, aos pais, nem tudo se pode dizer, não são todas as palavras permitidas em quaisquer circunstâncias. Estes «tabus da palavra», chamados por Foucault de «direito privilegiado ou exclusivo do sujeito que fala» (Foucault [1976] 2011, 9), tentam reafirmar uma soberania no discurso heterossexual e um silenciamento de qualquer discurso destoante. Desse modo, com a palavra proibida, o

Conforme vídeo com o pronunciamento do deputado federal Jair Bolsonaro disponível em $<$ https://www.youtube.com/watch?v=ONfPCxKdGT4\&feature=player_embedded $>$. 
poder se exerce de forma mais intensa. Há, também, na fala do parlamentar, mais do que um embate que traduz as lutas ou os sistemas de dominação, uma verdade - construída e sustentada por instituições como a religião - que indica a tentativa de se apoderar ainda mais dos discursos - que estarão presentes na escola - e, consequentemente, do poder (Foucault [1976] 2011).

\section{Senador Magno Malta}

O Senador Magno Malta foi reeleito em 2010. Além de político, é também pastor evangélico. O seu pronunciamento, ora em apreciação, foi proferido na tribuna do Senado. Nele, quem fala é alguém que tem o poder político de aprovar ou não projetos de interesse da população, seja ela minoria ou maioria. Ao se pronunciar, identifica-se, a partir dos enunciados, a posição de diferentes sujeitos. O Senador ora se apresenta como «eu» ora como «nós», sendo que o «nós» refere-se à instituição que ele integra como Senador da República:

o que nós queremos discutir com ele - a Frente da Família - é esse kit. [...]

[...]

O que nós precisamos resgatar é valor de família, Presidente Dilma. [...].

[...]

Então nós temos que resistir ao Governo, nós temos que resistir ao Sr. Haddad com esse kit $[\ldots]$.

$[\ldots]$

[...] de fato nós não podemos criminalizar um país inteiro.

$[\ldots]$

[...] o que nós precisamos dar em relação à Constituição é respeito a todos os cidadãos. ${ }^{4}$

Já quando utiliza a primeira pessoa do singular, quem fala expressa sua indignação e opiniões pessoais:

Eu estou vindo de uma reunião na Câmara, [...].

[...]

Eu estou olhando para o Brasil para afirmar o seguinte, Senador [...]: esse kit homossexual nas escolas fará das escolas do Brasil verdadeiras academias de homossexuais. [...]. Agora nada mais do que o respeito, estão passando do limite.

Senador [dirige-se a outro senador], V. Ex a é católico praticante e sabe que Deus criou macho e fêmea. Esta Casa não fará um terceiro sexo com uma lei porque há de esbar-

«Pronunciamento de Magno Malta em 24/05/2011», Senado Federal. Disponível em <https:// www25.senado.leg.br/web/atividade/pronunciamentos/-/p/texto/388285>. 
rar nos homens e mulheres que acreditam em princípios, e uma minoria barulhenta jamais se sobreporá a uma grande maioria, que é a família neste País.

[...]

Eu tenho uma criança de nove anos em casa. Ela perguntou: Pai, então, agora, quer dizer que $[\ldots] .^{5}$

Em relação ao sujeito do enunciado, ele é diferente do autor do texto ou do sujeito que enuncia. Foucault o define como «um lugar determinado e vazio que pode ser efetivamente ocupado por indivíduos diferentes» ([1969] 2000, 108). A análise do sujeito no desempenho da função enunciativa exige não a verificação de alguém que a proferiu, mas a determinação da posição «que pode e deve ocupar todo indivíduo para ser ([..] sujeito» ([1969] 2000, 108). A relação da posição do sujeito com os lugares institucionais, conforme explica Foucault ([1969] 2000), é que define o sujeito, ou seja, o lugar de onde fala. O lugar social de onde o Senador Magno Malta fala possibilita-lhe um empoderamento como sujeito do discurso que se inscreve em uma determinada formação discursiva e, por isso, se apropria de um poder/saber que se materializa na sua prática discursiva como um discurso de verdade.

A afirmação do Senador de que o kit homossexual fará das escolas do Brasil verdadeiras academias de homossexuais, que Deus criou macho e fêmea e que a Casa não fará um terceiro sexo mostra que o lugar de onde o Senador fala produz efeitos de sentido por apropriações de regiões do saber/poder/dizer, os quais atuam de maneira constitutiva na sedimentação da formação discursiva na qual se inscreve. Identifica-se uma dispersão de enunciados, ou seja, há uma interdiscursividade, pois o sujeito, sendo uma função, assume vários papéis sociais (Gregolin 2006). A análise do sujeito integra o reconhecimento de relações entre vários enunciados e sistemas de enunciabilidade que definem os regimes de saber e verdade de uma época. Como Senador da República, ele constrói um discurso que é atravessado por outros discursos de cunho moral e religioso que sustentam a heteronormatividade, já que ele também ocupa o lugar de sujeito pastor evangélico e de cidadão pai de família que tem filhos na escola. O Projeto Escola sem Homofobia, apelidado por seus detratores de «kit gay», e o termo «ideologia de gênero» na voz de políticos e religiosos foram as estratégias discursivas que prepararam o terreno, que teve início em 2010, e que serviram de alicerce para criar o pânico moral na sociedade brasileira, o que culminou com as eleições presidenciais em 2018. Toda a campanha do candidato eleito foi baseada nesses discursos e alimentada por eles. Seu discurso de posse reiterou a agenda ultraconservadora gestada desde 2010, com vistas a interditar discussões de gênero e sexualidades a partir do ambiente escolar, chegando a toda a sociedade. www25.senado.leg.br/web/atividade/pronunciamentos/-/p/texto/388285>. 


\section{Discurso de posse do Presidente em janeiro de 2019}

Vamos unir o povo, valorizar a família, respeitar as religiões e a nossa tradição judaicocristã, combater a ideologia de gênero, conservando nossos valores. O Brasil voltará a ser um país livre das amarras ideológicas. ${ }^{6}$ (destaque acrescentado)

Nesses discursos, emerge um sentido de que discutir as questões de gênero e diversidades no âmbito da escola é visto como uma espécie de peste que necessita de combate para que não se prolifere. Desde seu surgimento, a expressão «ideologia de gênero» carrega em seu bojo um sentido pejorativo. Por meio dela, setores mais conservadores da sociedade protestam contra atividades que buscam falar sobre a questão de gênero e assuntos relacionados - como sexualidade - nas escolas. Boa parte da sociedade concorda com o sentido negativo empregado no termo «ideologia de gênero»e, geralmente, teme que, ao falar sobre as questões mencionadas, a escola vá contra os valores da família (Oliveira et al. 2019).

\section{Discurso de posse do ministro da Educação, janeiro de 2019}

À agressiva promoção da Ideologia de Gênero, somou-se a tentativa de derrubar as nossas mais caras tradições pátrias. Essa tresloucada onda globalista, tomando carona no pensamento Gramsciano e num irresponsável pragmatismo sofístico, passou a destruir, um a um, os valores culturais em que se sedimentam as nossas instituições mais caras: a família, a Igreja, a escola, o Estado e a Pátria, numa clara tentativa de sufocar os valores fundantes da nossa vida social. ${ }^{7}$

Nesse discurso, emerge a ideia da existência de uma conspiração, cujo objetivo do plano seria destruir o patrimônio cultural e moral do cristianismo. Esses líderes constroem suas verdades intencionalmente com a finalidade de provocar certo pânico moral na população que, sendo religiosa, acredita que isso possa acontecer. Essa constatação encontra consonância nos postulados de Foucault ([1976] 2011), em relação à ideia de que a verdade pertence a este mundo, pois há uma multiplicidade de coerções e efeitos regulamentados de poder que produzem as verdades. As verdades produzidas por esses líderes têm como consequência gerar mais ódio ao grupo LGBT.

\footnotetext{
6 «Discurso proferido pelo Sr. Jair Messias Bolsonaro, por ocasião de sua posse no cargo de Presidente da República Federativa do Brasil», Sessão Conjunta do Congresso Nacional, em 1 de janeiro de 2019. Disponível em <https://escriba.camara.leg.br/escriba-servicosweb/pdf/54479>.

7 Disponível em <https://novaescola.org.br/conteudo/14877/discurso-de-ricardo-velez-rodriguez-que-mudancas-esperar-no-mec $>$.
} 
No pronunciamento de posse, em janeiro de 2019, a ministra da Mulher, Família e Direitos Humanos deu o seu recado

Acabou a doutrinação ideológica de crianças e adolescentes no Brasil. Neste governo, menina será princesa e menino será príncipe. Está dado o recado. Ninguém vai nos impedir de chamar nossas meninas de princesas e nossos meninos de príncipes. ${ }^{8}[\ldots]$ No Brasil tem meninos e meninas.

Quando uma ministra aborda que acabou a doutrinação ideológica, ela afirma que neste governo será diferente. Homem será homem e mulher será mulher, assim não se respeitarão outras expressões de sexualidade, configura-se desta forma o não reconhecimento da diversidade sexual, excluindo milhões de pessoas que fogem ao padrão heteronormativo.

Os excertos acima mostram que a discussão sobre gênero e diversidades na escola se traduz em sentidos de desconforto e indignação por parte desses líderes. Os efeitos de sentidos que emergem desses discursos em relação às ações educativas que abordam estes temas constituem, na visão deles, um péssimo exemplo para as famílias e uma ameaça de destruição dos pilares da sociedade atual regida por uma moral conservadora. Essas reflexões revelam que esse é o pensamento que está refletido na instituição escolar, ou seja, as verdades únicas, os modelos hegemônicos da sexualidade «normal», mostrando o jogo de poder e interesses envolvidos na intencionalidade de sua construção.

\section{Conclusões}

No contexto contemporâneo brasileiro, pode-se concluir que há nos discursos proferidos por algumas personalidades políticas e religiosas a subversão dos conceitos de gênero e sexualidades - tratados como «ideologia de gênero» (sic). Isso contribui para a instauração de um regime de saber, poder e verdade atravessado pelo pânico moral. «Ideologia de gênero», «imposição das minorias», «ataque às instituições família e igreja», «degenerescência da sociedade», pânico moral, coincidência entre sexo biológico e gênero, orientação sexual única e opressora às demais, dentre outros pontos, são elementos característicos nos discursos aqui apresentados. Vale destacar que esses elementos podem ser caracterizados como discursos, pois são práticas que obedecem a regras. Também atendem, de acordo com a teoria foucaultiana, a dois princípios, regularidade e dispersão, formando um sistema. Entendemos importante essa caracterização, pois, para Fou-

Disponível em <https://www.plural.jor.br/colunas/caixa-zero/meninos-vestem-azul-meninasvestem-rosa-esta-e-a-verdadeira-ideologia-de-genero $>$. 
cault, onde houver discurso, há estratégias e a tentativa de se apoderar mais das relações de saber e poder.

A estratégia é o mais importante elemento na manipulação de forças das relações de saber e poder. As ações no interior de uma sociedade são formadas a partir delas e por elas se manifestam. Por estratégia, em consonância com a obra foucaultiana, entende-se desde a escolha dos meios empregados para se chegar a um fim (uma racionalidade empregada para se atingir um objetivo), passando pela maneira pela qual se tenta ter uma vantagem sobre o outro, até ao conjunto dos procedimentos que são utilizados num confronto com o objetivo de privar o oponente dos seus meios de luta e reduzi-lo a ponto de renunciar ao embate. Os discursos selecionados para esta análise são exemplares da estratégia de aniquilar o outro, o divergente. Ainda que não haja qualquer sustentação teórica que justifique a ação dos parlamentares em análise, como estratégia, constitui-se o discurso, com sua regularidade e dispersão, num continuum que intenta, no corpo das relações de saber e poder, formar sujeitos que reproduzam ainda mais a opressão.

Considera-se de grande relevância estudar sobre o tema por se entender que a exclusão fere a dignidade da pessoa humana. A LGBTfobia é naturalizada discursivamente e se fundamenta em discursos de verdades sobre a sexualidade, atravessadas pelas relações de poder/saber, representadas pelas instituições religiosas e políticas que legitimam a violência e reforçam as atitudes de intolerância.

\section{Referências bibliográficas}

Abramovay, Miriam, Mary G. Castro, e Lorena B. Silva. 2004. Juventude e sexualidade. Brasília: UNESCO.

Barros, Antonio T., e Cláudia R. F. Lemos. 2018. «Política, pânico moral e mídia: controvérsias sobre os embargos infringentes do escândalo do Mensalão.» Opinião Pública 24 (2): 291-327. DOI: https://doi.org/10.1590/1807-01912018242291

Borges, Rafaela Oliveira, e Zulmira Newlands Borges. 2018. Pânico moral e ideologia de gênero articulados na supressão de diretrizes sobre questões de gênero e sexualidade nas escolas. Revista Brasileira de Educação, 23. DOI: https://doi.org/10.1590/s141324782018230039

Borillo, Daniel. 2010. Homofobia: História e crítica de um preconceito. Belo Horizonte, MG: Autêntica Editora.

Deleuze, Gilles. (1986) 2005. Foucault. 5. ${ }^{\text {a }}$ reimpr. Traduzido por Claudia Sant'Anna Martins. São Paulo: Brasiliense. Disponível em http://conexoesclinicas.com.br/wp-content/ uploads/2015/12/DELEUZE-G.-Foucault1.pdf

Foucault, Michel. (1969) 2000. Arqueologia do Saber. Traduzido por Luiz Felipe Baeta Neves. Rio de Janeiro: Forense Universitária.

Foucault, Michel. (1976) 2011. História da sexualidade 1: A vontade de saber. São Paulo: Graal.

Foucault, Michel. (1970) 2013. A ordem do discurso. 23. a ed. Traduzido por Laura Fraga de Almeida Sampaio. São Paulo: Edições Loyola. Disponível em https://moodle.ufsc.br/ pluginfile.php/1867820/mod_resource/content/1/FOUCAULT $\% 2 C \% 20$ Michel $\% 20$ $-\% 20 \mathrm{~A} \% 20$ ordem $\% 20 \mathrm{do} \% 20$ discurso.pdf 
Foucault, Michel. (1982) 2013. «Sujeito e Poder.»In Michel Foucault-uma trajetória filosófica: para além do estruturalismo e da hermenêutica, organizado por Hubert L. Dreyfus e Paul Rabinow, 278-291. 3. ${ }^{\text {a }}$ ed. Traduzido por Vera Portocarrero e Gilda Gomes Carneiro. Rio de Janeiro: Forense Universitária.

Gregolin, Maria do Rosario. 2006. «AD: descrever-interpretar acontecimentos que fundem linguagem e história.» In Estudos do texto e do discurso: Mapeando conceitos e métodos, organizado por Pedro Navarro, 19-34. São Carlos, SP: Claraluz.

Gregolin, Maria do Rosario. 2007. «Análise do discurso e mídia: A (re)produção de identidades.» Comunicação, mídia e consumo 4 (11): 11-25. Disponível em http://revistacmc. espm.br/index.php/revistacmc/article/viewFile/105/106

Junqueira, Rogério Diniz. (org.). 2009. Diversidade sexual na educação: Problematizações sobre a homofobia nas escolas [Edição Eletrônica]. Disponível em http://www.ded.ufla.br/ generoesexualidade-ei/imagens/homofobia_na_escola.pdf

Minayo, Maria C. de Souza. 2010. O desafio do conhecimento: Pesquisa qualitativa em saúde. 12. ${ }^{\text {a }}$ ed. São Paulo: Hicitec.

Ministério da Educação. 2012. «Resolução n 2, de 30 de janeiro 2012. Define Diretrizes Curriculares Nacionais para o Ensino Médio.» In Diário Oficial da União, 31 de janeiro de 2012, Seção 1: 20-21. Disponível em https://www.jusbrasil.com.br/diarios/ DOU $/ 2012 / 01 / 31 /$ Secao- 1 ? $p=2$

Miskolci, Richard. 2007. Pânicos morais e controle social: reflexões sobre o casamento gay. Cadernos Pagu, 28: 101-128. DOI: https://doi.org/10.1590/18094449201900550011.

Oliveira, Cleide Ester. 2014. Discursos, Homofobia e Políticas de Direitos Humanos. Tese de Doutorado. Universidade Federal da Paraíba, João Pessoa, Brasil.

Oliveira, Cleide E., Nadir F. B. Bittencourt, Veralúcia G. de Souza, Paulo S. Pimentel, Katia T. P. Ormond, e Isabel C. da Silva. 2019. «Gêneros, sexualidades e educação: estratégias discursivas como ferramentas de poder na construção do pânico moral que refletiram nas eleições do Brasil em 2018.» In Atas do 8. ${ }^{\circ}$ Congresso Ibero-Americano em Investigação Qualitativa, vol. 1, organizado por António Pedro Costa, Susana Oliveira e Sá, Paulo Castro, Dayse Neri de Souza, 859-870. Aveiro: Ludomedia. Disponível em https://proceedings.ciaiq.org/index.php/CIAIQ2019/article/view/2312

Reis, Neilton, e Raquel Pinho. 2016. «Gêneros não-binários: identidades, expressões e educação.» Revista Reflexão e Ação 24 (1): 7-25. DOI: https://doi.org/10.17058/rea.v24i1. 7045.

Silva, Gilson Pequeno, Isabel Cristina Silva, e Raquel Martins Fernandes Mota. 2018. «Panorama geral da pesquisa 'Violação dos Direitos Humanos e Bullying no Contexto Escolar' do grupo de pesquisa em humanidades e sociedade contemporânea do IFMT.» In Semiedu 2018-30 Anos do PPGE, 3535-3545. Cuiabá. Disponível em http://eventosacademicos.ufmt.br/public/conferences/8/schedConfs/36/accommodation-15. pdf\#page $=3535$

Cleide Ester de Oliveira. Doutora em Psicologia Social pela Universidade Federal da Paraíba (UFPB). Mestre em Estudos da Linguagem pela Universidade Federal de Mato Grosso (UFMT). Participa do Grupo de Pesquisa em Humanidades e Sociedade Contemporânea.

Endereço eletrónico: cleidester@hotmail.com 
Nadir de Fátima Borges Bittencourt. Doutora em Psicologia Social pela Universidade Federal da Paraíba (UFPB). Mestre em Letras pela Universidade de Nancy II, França. Coordenadora do grupo de pesquisa GEEJA/IFMT - Grupo de Estudos sobre Educação de Jovens e Adultos. Membro dos grupos de pesquisa GELLI/IFMT - Grupo de Estudos em Ensino de Línguas e Literatura; Núcleo de Pesquisa em Geoprocessamento Ambiental-IFMT; Núcleo de Pesquisa e Estudos sobre o Desenvolvimento da Infância e Adolescência (NUPEDIA/UFPB).

Endereço eletrónico: nadir.bittencourt@cba.ifmt.edu.br

Veralúcia Guimarães de Souza. Doutora em Linguística pela Universidade de Brasília, participa do Grupo de Pesquisa em Humanidades e Sociedade Contemporânea e da Rede Latino-Americana de Analista de Discurso. Atua com pesquisa na área de Análise de Discurso Crítica e Gramático-Sistêmico Funcional.

Endereço eletrónico: veralucia.souza@blv.ifmt.edu.br

Paulo Sesar Pimentel. Doutor em Psicologia (UFF). Mestre em Estudos da Linguagem (UFMT). Professor no Instituto Federal de Mato Grosso. Pesquisador na Universidade Federal de Mato Grosso (UFMT).

Endereço eletrónico: paulo.pimentel@blv.ifmt.edu.br

Kátia Terezinha Pereira Ormond. Doutora em Estudos de Cultura Contemporânea pela Universidade Federal de Mato Grosso (ECCO). Mestre em História pelo Programa de Pós-Graduação em História pela mesma universidade (2011). Pesquisadora em História da Alimentação e gastronomia em Mato Grosso, com ênfase em hábitos alimentares e sociabilidades.

Endereço eletrónico: katia.ormond@blv.ifmt.edu.br

Isabel Cristina Silva. Mestre em Ensino pelo Programa de Pós-Graduação em Ensino (PPGEn) - IFMT/UNIC - Instituto Federal de Educação Ciência e Tecnologia de Mato Grosso/Universidade de Cuiabá. Grupo de Pesquisa em Humanidades e Sociedade Contemporânea (GPHSC).

Endereço eletrónico: isabel.silva@plc.ifmt.edu.br

Artigo recebido a 02 de fevereiro e aceite para publicação a 08 de maio de 2020. 